\title{
Diagnostic Clues and Management of ectopic Pregnancy in Sir Salimullah Medical College and Mitford Hospital, Dhaka
}

\author{
NAZIA ISLAM
}

\begin{abstract}
:
Background: Ectopic pregnancy is a common clinical condition. Diagnosis and management of this condition is necessary in due to day practice.

Methods: A cross sectional study on ectopic pregnancy was conducted in Sir Salimullah Medical College and Mitford Hospital (SSMC \& MH), Dhaka, with the objective to analyze the risk factors and assess the results of management with respect to maternal morbidity and mortality of ectopic pregnancy during the last two years.

Result: Fifty patients were admitted with ectopic pregnancy from $1^{\text {st }}$ January 2008 to $31^{\text {st }}$ December 2010. Frequency of ectopic pregnancy were 1.5\% of total 3252 pregnancies. Risk factors were found in $45 \%$ of cases. Surgical treatment were performed in total 43 patients. There was one heterotrophic pregnancy and one case of abdominal pregnancy. Four patients were given intramuscular Methotrexate and two un-ruptured ectopics resolved spontaneously after by expectant management.

Conclusion: Conservative management was an option but surgical treatment was done more often because of late referrals. Screening of high risk cases, early diagnosis and early intervention would reduce the morbidity in ectopic pregnancies.
\end{abstract}

\section{Introduction:}

Ectopic pregnancy is a major health problem for women of child bearing age. Rupture ectopic pregnancy is the most serious gynaecological emergency due to internal haemorrhage, shock and sepsis. It is the leading cause of maternal morbidity and mortality. it accounts for $9 \%$ of all pregnancy related death ${ }^{1}$. Since 1970,the frequency of ectopic pregnancy has increased six folds and presently it is seen in $2 \%$ of all pregnencies ${ }^{2}$. The incidence of ectopic pregnancy has increased from 4.5/1000 in 1970 to $19.7 / 1000$ in $1992^{3}$. This may be due to higher incidence of salpingitis, an increase in ovulation induction and tubal ligation. In a study it has been fund that among 150 mothers who were brought dead in hospital, at least two were due to ruptured ectopic pregnency ${ }^{4}$. In order to decrease maternal mortality and morbidity due to ectopic pregnency, there is a need for early diagnosis. The availability of sensitive Beta hCG and high resolution sonography can make early diagnosis and reduce mortality rate ${ }^{5}$. The aim of the study was to review the data of ectopic pregnancy during the last 2 years, analyze the risk factors and assess the result of management in corelation to morbidity and mortality.

\section{Material and Methods:}

This cross sectional study was carried out at the department of obs and gynae of SSMC and MH from 2008 to 2010. From all the admitted patients' only cases of ectopic pregnency were included in the study. After formulation of aim of the study a clinical data sheet was made for recording all the information of the pregnant women. A verbal informed written consent was taken from each woman. After history taking, duration of gestational age was estimated from $1^{\text {st }}$ day of L.M.P and early USG reports. Patient's presenting complaints namely duration of amenorrhoea, abdominal pain, per vaginal $(p / v)$ bleeding, syncopal attack, urinary problems were recorded. Presence of any risk factors like PID, H/O abortions or M.R. and any pelvic surgery specially

Address of Correspondence: Dr. Nazia Islam, Specialist, Dept. of Mother and Child Care, BRB Hospitals Ltd, East Razabazar (Former Gastro Liver Hospital), Panthopath, Dhaka-1215 email-naziaislam1978@gmail.com, Mobile-01715437494. 
appendisectomy etc were looked for and recorded. For confirmation of the diagnosis serum ${ }^{2} \mathrm{hCG}$, Transvaginal sonography (TVS) was done and culdocentesis was performed in necessary cases. Plan of management of patient with ectopic pregnancy was decided according to the condition of patient. Emergency operation were planned and performed accordingly.

\section{Result:}

Among total 1200 admitted cases 60 patients presented with ectopic pregnancy. Finally analysis of data was possible for 50 patients. The frequency of ectopic pregnancy was $1.3 \%$. Among them 30 patients presented with disturbed and 10 with unruptured ectopic and 10 patients had tubal abortion. Majority of patients (74\%) were of age group of 21-30 years. Regarding parity ectopic pregnancy was found closely related to low parity i.e. para1 in $30 \%$ cases and only $10 \%$ had parity $>4$.

Table-I

Risk Factors $(N=50)$

\begin{tabular}{lcc}
\hline Risk Factors & Frequency & Percentage \\
\hline H/O abortion/MR & 15 & $30 \%$ \\
H/O subfertility & 5 & $10 \%$ \\
Pelvic infection & 12 & $24 \%$ \\
H/O Appendicectomy & 1 & $2 \%$ \\
H/O IUCD insertion & 7 & $14 \%$ \\
\hline
\end{tabular}

Amongst the risk factors commonest was history of abortion \& MR and pelvic infection (Table-I).

Table-II

Presenting symptoms

\begin{tabular}{lcc}
\hline Symptoms & Number & Percentage \\
\hline Abdominal pain & 50 & 100 \\
Period of amenorrhea & 38 & 76 \\
P/V bleeding & 25 & 50 \\
Early pregnancy symptoms & 21 & 42 \\
Syncopal attack & 22 & 44 \\
Shock (collapse) & 15 & 30 \\
\hline
\end{tabular}

Commonest presenting symptoms were abdominal pain which was present in $100 \%$ cases, others in order of frequency were periods of amenorrhoea, $\mathrm{p} /$ $v$ bleeding, syncopal attack(Table-II).

The most frequent physical findings were abdominal tenderness which was present in $100 \%$ cases, cervical excitation was present in $84 \%$ cases and palpable adenexal mass was noted in $16 \%$ cases . On admission 32 patients were found severely anaemic and required blood transfusion.

Serum ${ }^{2}$ hCG was positive in all cases and ranged between $65.88-18,843 \mathrm{mIU} / \mathrm{ml}$. Urine hCG was performed in 40 patients. It was positive in $74 \%$ and negative in $26 \%$ cases . The size of ectopic mass on ultrasonogram ranged between $1.2 \times 2.5-7.0 \times 6.2$ $\mathrm{cm}$ ( mean $3.6 \times 3.5 \mathrm{~cm}$ ).

Table-III

Sites of ectopic pregnancy $(N=50)$

\begin{tabular}{lcc}
\hline Sites & Number & Percentage \\
\hline Isthmas & 16 & $32 \%$ \\
Ampulla & 26 & $52 \%$ \\
Interstitial part & 06 & $12 \%$ \\
Abdominal & 1 & $2 \%$ \\
$\begin{array}{l}\text { Rudimentary horn of } \\
\text { bicornuate uterus }\end{array}$ & 1 & $2 \%$ \\
\hline
\end{tabular}

In $96 \%$ cases ectopic was tubal ectopic pregnancy. Ampulla was the commonest site (52\%), next was Isthmus (32\%). Abdominal pregnancy and ectopic in rudimentary hor of bicornuate uterus occurred in 1 patient each (Table-III).

Table-IV

Types of interventions $(N=50)$

\begin{tabular}{lcc}
\hline Types of interventions & Number & Percentage \\
\hline Linear salphingostomy & 07 & $15 \%$ \\
Unilateral salphingectomy & 33 & $66 \%$ \\
Others & 10 & $10 \%$ \\
\hline
\end{tabular}

Among surgically treated patient $33(66 \%)$ had unilateral salpingectomy. Linear salphingostomy were done in $7(15 \%)$ patients. Tubal expression of ectopic gestation by milking of tube was done in one patient (Table-IV). Histopathological report confirmed ectopic pregnancy in all surgically treated patients.

Two patients were managed expectantly and successfully. She had an unruptured ectopic pregnancy with ${ }^{2} \mathrm{hCG}$ level of $522 \mathrm{lu} / \mathrm{ml}$ and gestationl sac size $2.2 \times 1.5 \mathrm{~cm}$. She was monitored by weekly serial ${ }^{2}$ hCG levels and usg done till ectopic pregnancy resolved. For medical treatment with single dose Methotrexate $50 \mathrm{mg} / \mathrm{m}^{2} \mathrm{IM}$, four patients 
were selected. All were primigravida and came within 9 weeks amenorrhoea. Amongst one patient was asymptomatic, diagnosed incidentally on USG, while the rest presented with bleeding per vaginum. Initial ${ }^{2}$ hCG levels of the patients ranged between 5937$7201 \mathrm{IU} / \mathrm{ml}$ and adnexal mass size $4.4 \times 2.7-4.6 \times 3.9$ $\mathrm{cm}$. All patients showed declining ${ }^{2} \mathrm{hCG}$ level, but one patient readmitted in emergency on $28^{\text {th }}$ day of Methotrexate administration with acute abdomen and surgical intervention was required for the rupture ectopic pregnancy. The other patients remained well and their ectopic resolved completely after 48 days. Considering morbidity level there was no complications, patients who had expectant management. One patient had heterotrophic pregnancy and one had abdominal pregnancy. Both were treated by surgical management. Among the surgically treated patient, eleven patients had fever, five had UTI and one had wound infection. There was no mortality in this series.

\section{Discussion:}

This study was conducted on admitted patients of SSMC and MH who were diagnosed clinically as ectopic pregnancy. The frequency of ectopic pregnancy was $1.3 \%$. The incidence of ectopic pregnancy varies greatly throughout the world ranging from 1 in 28 to 1 in $300^{6}$. In our country, unsafe abortion leading to PID is the main reason to occur ectopic pregnancy.

Ectopic pregnancy may occur at any age from menarchae to menopause. In present study $46 \%$ bof the patients were in age group 21-25years.The youngest age group patient was $<20 y$ rs constitutes $6 \%$ of the cases. Almost similar observations have been made Zabeen ${ }^{7}$, a study in Dhaka Medical College. Fernandes ${ }^{8}$ found that $65 \%$ patient ranged from $25-35$ years, $6 \%$ were adolescents. Siddiqua \& colleagues ${ }^{9}$ found $45 \%$ of their patients were between 25-35 years. General symptoms of ectopic pregnancy include the classical triad of pain, amenorrhoea and vaginal bleeding. In this series $100 \%$ presented with abdominal pain, $76 \%$ with period of amenorrhoea and $50 \%$ with $\mathrm{p} / \mathrm{v}$ bleeding. Study findings are similar to the study findings of Nahar .K 10 where $100 \%$ patient presented with abdominal pain, $70 \%$ with period of amenorrhoea and $50 \%$ with $\mathrm{p} / \mathrm{v}$ bleeding. In another study Tancer et al ${ }^{11}$ showed that $90 \%$ of patients had abdominal pain and $63.8 \%$ had abnormal vaginal bleeding. Siddiqua
\& colleagues ${ }^{9}$ observed that $95 \%$ patients presented with abdominal pain, $65 \%$ period of amenorrhoea and $7 \%$ cases with irregular $p / v$ bleeding in their study . In this study $46 \%$ patient gave the history of amenorrhoea of 6-8 weeks which is almost similar to other studies. of the study ${ }^{9,10}$.

Infertility or subfertility is a risk factor for ectopic pregnancy. In the present study history of infertility was present in $10 \%$ of cases but the incidence was higher in the study of Siddiqua \& colleagues ${ }^{9}$ which was $28 \%$. History of previous induced abortion increase the risk of ectopic pregnancy 14 folds. In the current study $30 \%$ cases had previous history of menstrual regulation or abortion. In a study of Zabeen $^{7} 48 \%$ cases had previous history of MR or abortion. Use of IUCD can place a woman at an increased risk of ectopic pregnancy. In this study $14 \%$ were IUCD users. Nahar ${ }^{10}$ observed $16 \%$ and Zabeen ${ }^{7}$ observed that $34 \%$ patient were IUCD users. Veldhuis et al ${ }^{12}$ observed the incidence of ectopic pregnancy in IUCD users was 0.6 to $1.1 \%$ per year. Coste, J.et al ${ }^{2}$ observed the rate of contraceptive failure (mostly IUCD failure) associated with ectopic pregnancy was $29 \%$. The disparity may be due to the fact that in this study $40 \%$ of study population did not use any contraceptive method. The incidence of pelvic inflammatory disease (PID) has increased among the young women. Infection following induced abortion is the major cause of PID and the risk of ectopic pregnancy 10 times higher in areas with a high incidence of illegal abortion ${ }^{13}$ and 6 times higher following clinical salpingitis ${ }^{14}$.Several case control studies have reported a strong association between ectopic pregnancy and Chlamydia trachomatis infection ${ }^{15,16}$ and Gonococcal infection. Unfortunately samples of the present study were not screened for these organisms. In present study $24 \%$ patient had pelvic infection, similar findings (24\%) was found by Nahar K ${ }^{10}$. Smith ${ }^{17}$ found $50 \%$ of women with ectopic pregnancy had a history of PID. Zabeen ${ }^{7}$ observed $48 \%$ patients had PID. The difference is due to many women having PID is asymptomatic so the actual number of patient suffering from PID is difficult to obtain. The mode of presentations of ectopic pregnancy may be acute, chronic or subacute. Acute presentation is usually associated with tubal rupture and massive intraperitoneal haemorrhage leading to acute abdominal pain and cardiovascular collapse. Siddiqua \& colleagues ${ }^{9}$ observed $22 \%$ patients presented with collapse and Nahar ${ }^{10}$ found $60 \%$ 
cases presented with collapse. This disparity may be due to early diagnosis of ectopic pregnancy before rupture. Collapse is due to hypovolumia and it depends upon amount of blood loss and previous haemoglobin status of the patient.

The chronic variety presents with localized tenderness and muscle guard in the lower abdomen, possibly with adnexal mass due to small amount of retroperitoneal bleeding as in tubal abortion and tubal mole. In this study $16 \%$ of the cases had palpable lump. Kumar ${ }^{18}$ reported that $92 \%$ of patients had combination of complex mass and positive beta hCG test .Zabeen ${ }^{9}$ found adnexal mass in $10 \%$ cases and Nahar ${ }^{10}$ found in $8 \%$ case. In this study abdominal tenderness was observed in $100 \%$ cases, . The findings is almost similar to the study of Tancer, ${ }^{11}$ and Zabeen ${ }^{7}$.

Tuomivara \& colleagues ${ }^{19}$ reported cervical excitation test positive in $51 \%$ cases and abnormal uterine bleeding in $76 \%$ of their patients. In my study movement of the produced pain in $84 \%$ of cases and abnormal uterine bleeding in $50 \%$ cases. Similar result was found by Nahar $^{10}$ and Zabeen ${ }^{7}$,cervical excitation test positive in $90 \%$ cases and abnormal uterine bleeding in $60 \%$ cases.

Ultrasound examination of the pelvis is widely used to evaluate clinically stable patients suspected of having ectopic pregnancy. In my study $76 \%$ was diagnosed by ultrasound .Zabeen ${ }^{7}$ had $92 \%$ ultrasonographically diagnosed case.

Ultra sound examination of pelvis is widely used to evaluate clinically stable patients suspected of having ectopic pregnency. In my study $76 \%$ was diagnosed by ultrasound.Zabeen ${ }^{7}$ had $92 \%$ ultrsonographically diagnosed case.

Culdocentesis was performed when there was a suspicion of ectopic pregnancy .Positive culdocentesis was found in $76 \%$ cases.Zabeen ${ }^{7}$ found $84 \%$ positive cases.

Among all of my patients laparotomy was done with resuscitation measures(when needed)and peroperative findings were evaluated the time of operation, $96 \%$ cases tubal pregnancy was found among which $75 \%$ affected in right tube and $25 \%$ in the left side.$Z a b e e n^{7}$ found $79 \%$ right sided tubal pregnancy and $\mathrm{Nahar}^{10}$ found $54 \%$ of right sided tubal ectopic pregnancy. During operation $62.5 \%$ of tubal ectopic pregnancy was found ruptured,20.83\% unruptured and $16.6 \%$ were aborted. There was $2 \%$ of abdominal pregnancy. In a study, by Zabeen ${ }^{7}$ there was $74 \%$ ruptured, $4 \%$ unruptured and $20 \%$ aborted.

Sites of ectopic pregnancy were ampullary $52 \%$,Isthmic $32 \%$,interstitial $12 \%$,rudimentary horn of a bicornuate uterus $2 \%$.Almost similar observation has been made by Nahar ${ }^{10}$ and Zabeen ${ }^{7}$ in a local study.Siddiqua, Alam, Khan $^{9}$ found ampullary $64 \%$,isthmic $19 \%$,fimbrial $12 \%$,corneal $0.67 \%$ and rudimentary horns of bicornuate uterus $2 \%$.

The other sided tube was examined and I found $75 \%$ cases of normal looking. In all cases tubes were found clinically pathological (i.e. inflamed, adhesion and hydrosalpinx). In my study there was no mortality from ectopic pregnancy during the study period.

Earlier and more accurate diagnosis has changed the optimum management of ectopic pregnancy towards more conservative .During laparotomy appropriate surgery for the cases were performed. Salpingectomy was more commonly performed as because the patients come to hospital at a later stage with shock.

In my study linear salpingostomy was done in $12 \%$ of cases as $20.83 \%$ of cases are present with unruptured ectopic pregnancy. Unilateral salpingectomy was done in $58 \%$ of cases. Salpingectomy with contralateral tubectomy in $18 \%$ cases, salpingo-oophorectomy in $8 \%$ cases. Other operations like resection of bicornuate uterus and total abdominal hysterectomy was done in $4 \%$ of cases.

Types of operation varied as revealed in different studies conducted by different workers. A study by Zabeen ${ }^{7}$ reported that salpingectom with contralateral tubectomy in $46 \%$, salpingectomy in $52 \%$ cases. The study result Siddiqua, Alam, Khan ${ }^{9}$ showed unilateral salpingectomy in $71 \%$,unilateral salpingectomy with other sided tubectomy in $24 \%$ and resection of rudimentary horn of bicornuate uterus in 10\% cases.

Here I must have to mention that there was no post operative complication.

\section{Conclusion:}

The incidence of ectopic pregnancy appears to be comparatively high in our community. Pelvic inflammatory disease being the important risk factor. The risk factors should be more clearly defined by 
nationwide large scale multi-centric study, so that measures can be taken to reduce or prevent the incidence. Such as Chlamydia trachomatis serology should be a routine investigation protocol in all cases of ectopic pregnancy.

In our country early diagnosis of ectopic pregnancy before rupture was very difficult because most of the patients came from remote area with low socioeconomic condition. They are illiterate, non compliant and not conscious about their health status and early diagnostic facilities are not available in remote area. So there is tittle role MTX therapy in my study population. So management option is limited to laparotomy followed by salpingectomy which is still the standard treatment in many cases.

Better diagnostic facilities should be made available in remote area of our country to diagnose the case at an early stage and only when we can diagnose an ectopic pregnancy at early stage we will be able to treat these patients in such a way, that there will be maximum fertility and minimum risk for a future ectopic pregnancy.

\section{References:}

1. Neerja Bhatla (ed) in: Jeffcoate's principles of Gynaecology, $6^{\text {th }}$ ed,London: Butterworth and co Ltd.1987.

2. Alen H.Decerney MD, Lauren Nathan MD. Current obstetric and Gynaecologyc diagnosis and treatment.10h ed. McGraw-Hill companies, Norwalk, connectinuc, Pg(265-270).

3. Obstretics and Gynaecology, vol II M.Sivasuriya edited by SS Ratnam, K Bhasker Rao,S.Arul Kumaran $2^{\text {nd }}$ ed, Orient Longman.

4. Anornu RI,k. Oluwole A,A budu OO, debajos.Risk factors for ectopic pregnancy in Lagos,Nigeria. Acta obstet Gynaecol Scand .2005Feb;84(2):184-8.

5. D. C. Dautta. Text book of Gynaecology, $4^{\text {th }} \mathrm{ed}$, Calcutta:New Central book agency 2003.

6. Hankins GD ,Clark SL, Cunningham FG, Gilstrap LC, Ectopic Pregnancy. In Pregnancy .In operative obstretics Norwalk,Conn: Appleton and Lange,1995:437-56.

7. Zabeen F: Clinical presentation, management and operative finding of ectopic pregnancy DMCH .Dhaka 1998; Dissertation.
8. Fernands AM, RibeiroLP, Morales Ftl, Sollero Cde A,Yamada EM. Prevelelence of ectopic pregnancy liable to surgical treatment in apublic hospital from 1995 through 2000.Rev Assoc. Med .Bras. 2004 Oct-Dec;50(4):436-6 Epub 2005 Jan 14.

9. Siddiqua $S$, Alam MM, Khan TMA ectopic pregnancy -A diagnostic dilemma. Bangladesh J.Obstet Gynaecol ,2004; vol-119(1):7-10.

10. Nahar K: Clinical presentation management and operative findings of ectopic pregnancy $\mathrm{DMCH}$. Dhaka 2005,Dissertation.

11. Tancer, ML,Delke, Veridiano NP.A fifteen year experiences with ectopic pregnancy. Surg. Gynaecol Obstel,1981;153;1979-82.

12. Veldhuis HM, Vos AG,Lagro-Janssen AL, Complications of the intrauterine in nulliparous and parous women. Eur J. Gen Pract 2004 Sep ;10(3):82-87.

13. Breen JL.A 21 year surgery of 654 ectopic pregnancies ,Am J. Obstet Gynaecol,1970;106(7):1007.

14. J. Bouyer, J. Coste H.Fernandez, JL Pouly, NJo-Spira Siites of ectopic pregnancy: a 10-gr sites of ectopic pregnancy: a 10-yr population based study of 1800 cases. Human reproduction,vol-17, No. 12 , 3224-3230 December,2002.

15. Risk B,Tan, S.L,Morcos, S,Riddle A et.AI. Heterotrophic pregnancies after in vitro fertilization and embryo transfer, Am j .Obstet .Gynaecol 1991;164: 161-4.

16. Bhuiyan SN, Begum .R. Ectopic pregnancy: New Horizons. The Orion. Jan 2001;8:18-18.

17. Dr.Smith Joseph F. Smith .Ectopic pregnancy Medical Library, 2005 May 25,Pg No-1-6.

18. Kumar A,Lec SS, Colin SS, Worg YC. Chia D, Rodeuberg A, Ratnam SS, Accurancy In diagnosis of ectopic pregnancy by trans vaginal ultrasound, Asia Ocean .J- obstet Gynaecol 1992;97; 904-908.

19. Tuomivara , L, Kappila A.Puolokkal. Ectopic pregnancy -an analysis of the etiology, diagnosis and treatment in 552 cases. Arch Gynaecol 1986;237:135. 